\title{
Assertiveness in Self-Fulfillment and Professional Success. Interpersonal Dynamics in the Didactic Relation
}

\author{
Jitaru Oana ${ }^{1}$, Anghel Ionica Ona ${ }^{2}$ \\ ${ }^{1}$ Department for Teacher Training, Technical University “Gheorghe Asachi”, Iasi, Romania \\ ${ }^{2}$ Department for Teacher Training, National University of Arts, “George Enescu”, Iași, Romania \\ Email: oana_gavri12002@yahoo.com
}

How to cite this paper: Oana, J., \& Ionica Ona, A. (2019). Assertiveness in Self-Fulfillment and Professional Success. Interpersonal Dynamics in the Didactic Relation. Psychology, 10, 1235-1247.

https://doi.org/10.4236/psych.2019.108079

Received: May 21, 2019

Accepted: June 27, 2019

Published: June 30, 2019

Copyright (C) 2019 by author(s) and Scientific Research Publishing Inc. This work is licensed under the Creative Commons Attribution International License (CC BY 4.0).

http://creativecommons.org/licenses/by/4.0/

\begin{abstract}
Assertive communication is a basic tool in the acquirements of a debutant teacher and the development of communicational skills in this respect becomes vital for his professional success. Thus, this paper sets out the concepts of pedagogy of the group and assertive communication in the light of the newest theories and researches and argues about the need of an integrated development of the components of assertiveness-initiation of communication, setting boundaries, constructive expression of feelings, strategies for the increase of self-esteem - to students, future professors. It explains the necessity and benefits of developing assertiveness in self-success as well as in professional success. The purpose of the study is to investigate the perceptions of the students who are in the final years, regarding their own assertive behaviours and how they understand the aim of assertive communication in didactic relationship. In this respect, we organized and conducted three exploratory workshop activities based on focus group. Our results provide clarification regarding the students' personal perspectives on how to build a teacher-student relationship, on the models provided and the acquired skills, on the effective strategies of self-assertion they use consciously related to conflict management and injustice situations, as well as techniques used to manage emotions in the context of didactic relationships. It highlights the specific educational needs of students and the benefits of the democratic pedagogical style, based on assertiveness.
\end{abstract}

\section{Keywords}

Group Pedagogy, Assertiveness, Assertive Classroom Discipline, Self-Assertion, Self-Fulfillment 


\section{Theoretical Approaches}

Group pedagogy is an active and interactive pedagogy that encourages pupils/ students to participate in teaching activity and the efficient use of all their resources, respecting their individuality. The teacher coordinates the processes that take place at the group level, developing the cooperative dimension. The teacher facilitates each participant's interactions with himself/herself, with his/her colleagues, with the teacher and the curricular content. The pupil/student is encouraged to expose his own way of thinking, to engage personally in the activity, to exploit the experience rationally, to confront his personal reflection and knowledge experiences with that of others (Bocoș, 2013: p. 321). Thus, through the established interactions, each participant contributes to structuring and supporting the collaborative learning group, in order to solve, through concerted and convergent efforts, a comprehensive and stimulating task. The teacher is aware and informed about the group processes, about the ways in which the dynamics of these processes are prefigurated and is prepared to facilitate mutual exchanges within and outside the group, to establish complex networks of inter-human communication, ensuring the cohesion of the group. The professor acts as a group facilitator who creates a team in which the members manifest through interactions, intellectual, verbal, social and affective emotional exchanges in a positive, constructive work environment.

Assertive behaviour is defined as any action that reflects the interest and needs of the individual, including the defence of his own rights without significant anxiety, the comfortable expression of their feelings, and assumes the defence of rights without denying the rights of others (Alberti \& Emons, 1970: p. 15). Thus, non-aggressive behaviour reflects the individual's difficulties in being on his side-difficulties in expressing desires, needs, thoughts and emotions.

Lazarus (1971) analyzes assertiveness and defines it as a social competence that helps the individual to adapt to social life, and Cornelius and Faire (1996: p. 93) consider assertiveness as the individual's communication option that helps him to support his position without blaming or treating the other person as an opponent. The essential features of assertiveness are also captured by John Agada, Kenneth A. Weaver, Prasad Kantamneni and Janice Stalling (1994: p. 1) in the following definition, which recognizes its roots in previous studies and researches (Bakker \& Bakker-Rabdau, 1973; Phelps \& Austin, 1987): promotes positive, direct, kind and goal-oriented behaviors, while maximizing the power and efficiency of social interactions. All of these purchases are possible through problem solving and conflict resolution, self-actualization and positive selfimage.

Ames (2009: p. 115) defines interpersonal assertiveness by the way in which a person responds to a situation where his/her position or interests are or may be in conflict with the position and interests of others. People will ask "how hard I should I push it", and the assertive answer lies between avoidance and passivity, on the one hand, and aggression and hostility on the other. Being between pas- 
sive and aggressive, assertiveness involves negotiating with others, and involves maintaining verticality and balance, while respecting the wishes and rights of others. Becoming assertive involves developing the consciousness of your own needs and desires and the belief that you have the right to ask for what you want. This means to treat your own needs with the same respect and dignity you give to others. Assertiveness assumes you stand up for yourselves and your rights without excusing yourself and without feeling guilty. Essentially, assertiveness involves the responsibility for the fulfilment of one's own needs in a manner that protects the dignity of others. People feel comfortable in the presence of assertive people because they know how these persons position themselves.

Assertive behaviour promotes positive, direct, polite, and goal-oriented behaviours while maximizing the power and efficiency of social interactions. The essential skills and attitudes that make up this domain and are part of assertiveness are: To say "no" when the situation asks for it; Advancing request as a favour; Expressing positive and negative feelings; Initiating and sustaining a conversation; Manifestation of the power of persuasion; The attitude of defending his/her own rights without breaking others; Self-esteem and the desire to affirm (Lazarus, 1973; Alberti \& Emons, 2008; Jung, 2014).

The development of assertiveness in the educational environment is a necessity highlighted by a series of researches that, over time, have shown that the assertive abilities of the teacher determine the development of social skills in pupils and even increase the academic performance. The management of class based on the assertive discipline promoted by Canter \& Canter (2001: p. 81) is based on a set of specific strategies that help the teacher constructively solve problems and challenges in the teacher-student relationship while creating a positive and constructive learning environment. The system that includes rewards, behavioural reinforcements and consequences is an educational strategy based on a firm and correct attitude of the teacher that facilitates empowerment, self-expression and mutual respect for each individual's needs. A survey conducted by Obey-Jordan (2007: p. 300) presents results that prove the development of pupils' social skills following the implementation of an assertive classroom discipline program.

The results of other researches also (Pânișoară, Sandu, Pânişoară, \& Duță, 2015: p. 204) demonstrate the students' need to receive an education based on interpersonal communication and the efficiency of developing the assertive style of communication. The authors argue that educating the students' negotiating potential leads to the development of a culture of consensus and cooperation. Education for assertiveness leads to increased communication skills due to the ability to better manage interpersonal relationships, the ability to express feelings in a comfortable manner and the ability to solve problems (Gultekin, Ozdemir, \& Budak, 2018: p. 398). Speed, Goldstein and Golfried (2018: p. 8) highlight the role of creativity in reducing depression and anxiety, increasing the self-esteem and satisfaction in interpersonal relationships.

Their application of assertive communication with students can be a challenge 
because it involves seeing students as equal human beings and treating them with respect, even if they will not always do so in return. It is necessary to develop a behavioral school policy based on positive expectations about how to communicate with the educational partners. The only necessary requirement is one that demands that any issue can be expressed firmly, politely and clearly, and that aggression is not tolerated.

An assertive communication is more effective and develops in a positive way as the young person knows more about his/her own emotions and the others. We can also say that assertive communication itself, in turn, creates favorable conditions for better self-knowledge as well as for others (Rusu, 2017: p. 125). Socio-economic relations increased the interest of the psychologists and the citizens towards assertiveness as a method of self-accomplishment and selfapproval (Peneva \& Mavrodiev, 2013: p. 7). Graham \& Rees (1991) includes a large number of examples and practical exercises of self-development and self-fulfillment, to help personal growth towards the implementation of assertive skills to achieve the desired goals, confidently expressing own opinion, dealing with rejection and criticism, building and maintaining self-esteem.

\section{Research Methodology}

The aim of the study is to collect (and interpret) empirical data that outline the perception of young people regarding their own assertive behaviors and the role of assertive communication in the didactic relationship. In order to accomplish this purpose, we organized and conducted three exploratory workshop activities based on focus group. Consultative seminars and workshops have been used for exploratory purposes in various studies that address extremely new subjects and in which literature is lacking or it is too minimal (Evanghelidis, 2005; Zappas, 2008; Whittake, 2010). This type of seminars allows a double contribution-the completion of scientific research data with empirical data, on the one hand, and the opening up of many new research perspectives, on the other hand, which has led us to choose them in this paper.

Students in the 3rd year at the National Art University "G. Enescu" Iasi who attended the training module for a teaching career within the Didactic Staff Training Department were invited to participate in the workshop with the topic "Assertive Didactic Communication between Potential and Challenge", a total of 40 invitations were emailed to the students. Twenty-eight of them have responded to our invitation: 11 students at the Faculty of Visual Arts and Design, 8 students at the Faculty of Music, Instrumental Interpretation Specialization and 9 students at the Faculty of Music-Music Pedagogy specialization. All the participants agreed to participate and disseminate the data produced through the workshop.

As we have specified, the three workshops were designed and were implemented according to the scenarios implied by the focus group method, a set of 11 semi-structured questions being the skeleton on which the debate was built 
for each of them (Krueger \& Casey, 2005; Bulai, 2000; Chelcea, 2004; Iluț, 1997; Morgan, 1998). The first two questions were destinated to introduce participants to the workshop issues and explore their perception of the conditions for effective communication in general, for a teacher-student communication specifically. A set of four questions was intended to collect data on evidence of assertiveness in participants' day-to-day behaviour, without explicitly saying that this competence is concerned: how to express positive or negative feelings, how express their uniqueness, how they react when their rights are violated. The following five questions explored the students' perception of the role of assertive competence in the teaching profession. Previously, starting from a suggestive didactic film (https://www.youtube.com/watch?v=JwjAAgGi-90), there was a brief update of the theoretical information on assertive communication and assertive behaviour.

Workshop 1, the one with the students of the Faculty of Visual Arts, took place during 120 minutes, Workshop 2, the one with the students from the Faculty of Music, Instrumental Interpretation specialization lasted 45 minutes and Workshop 3, the one with the students at the Faculty of Music, the Music Pedagogy specialization took place within 50 minutes. The data was recorded on audio support, transcribed and then processed after the thematic decoupage technique (Bulai, 2000; Krueger \& Casey, 2005).

In each of the three workshops a series of themes and subtopics have been outlined: 1) the significance of assertive communication; 2) the role of assertive communication in the teacher-student relationships, and 3) ways of expressing assertive competence.

As for the first theme, the significance of assertive communication, the participants shape the sphere of assertive communication through the following components: the formulation of a request in an open, free manner, the courage to express opinions without bias, the use of appropriate non-verbal language. Although with a reduced frequency, are also mentioned the emotional management skills in difficult situations and confidence in the ability to persuade others. In all three workshops, the predominant idea is that of open communication expressed through verbal and non-verbal language and the transparency of request. The third workshop emphasizes the importance of a calm, but at the same time, confident and firm attitude.

In the second theme, assertive communication in the teacher-student relationship, we have identified a number of facilitators and inhibitors of assertive didactic communication. The teacher is seen as a group facilitator. This is the first factor that pertains to assertive communication and, implicitly, the development of student's assertive abilities. The teacher is seen by students as the one who creates the educational environment that allows the expression of ideas, not just scientific studies, but also personal visions, building a cohesive and stimulating group. The teacher, as an adult and as a professional, is responsible for building a secure emotional environment in the group, is a facilitator of positive 
emotions and learning: "On the professional side, there must be more dedication to the facilitation of communication. If a barrier exists on the part of the pupil, for example, there is no fluency in communication, then the professor is the one who has to remedy the situation ... he will be a facilitator"; "The teacher could give you the feeling that you are important... and also to help us feel better with each other" (Workshop 1).

Students understand the constructive relationship between teacher and student as being mediated by empathy. In their view, empathy supports assertive communication and facilitates learning. "In the absence of empathy and assertiveness, there can be no constructive relationship between teacher and student and learning bottlenecks appear." "It can be a trampoline for the student if the teacher is willing to listen and understand when something bothers you. And so you become more ambitious, you develop..." "A barrier is created, and it builds up gradually, and you cannot move forward" (Workshop 2); "The teacher is responsible for the quality and efficiency of communication. For this it is important that he/she listens to the pupils' opinion, and tries to be empathetic" (Workshop 3).

For the second theme we also identified a sub-theme, blockages in assertive communication. Identifying the bottlenecks that appear in assertive communication and are expressed in the teacher's behavior that incites student frustration (and even indignation): being unwilling to listen to students- "The teacher should accept our opinion. Not just what they claim is correct."; the attitude of superiority (...) the teacher should not make you feel like you are the stupidest person on earth and he is the smartest one just because he is the teacher. "the anchoring in traditional methods when working with students"- the teacher should understand that some methods no longer work (...); turning a blind eye to students who are attending courses less often (Workshop 3); extreme attitudes, passivity or aggression- "In the case of passivity, students will no longer be interested in course, in the case of aggression ... the pupils will learn with fear and will not enjoy the course" (Workshop 1).

The third theme is about the assertive abilities and behaviors of students, and three other subheadings are linked to it: the expression of positive and negative emotions, asserting and defending your own rights, self-esteem and the desire for affirmation.

Regarding to the expression of positive and negative emotions our participants consider that is depending on how intimate the relationship is: "It matters how close a person is to you when expressing your emotions. Even if you are a direct person, when talking to strangers you say these things in a nice packaged manner. To those close to you, you can tell them directly what you think." (Workshop 1); "If you express your feelings (positive ones) in your circle of friends, they are happy for and you get a wave of more and more positive emotions (...). But with the negative emotions I try to deal with alone, without expressing them." (Workshop 2). Self-control in expressing emotions is important, 
but it comes after gaining awareness of the negative emotions and their consequences (both on the state of mind of the one with whom you communicate and on your own) and then the self-education towards a positive lifestyle. (Workshop 1). There are indicated techniques to express negative feelings: “... with negative feelings, because I read this somewhere, I try to be careful and not to work myself up very quickly. I started to make this change to my behavior. Situations appear, but I solve them calmly because I know that... these conflict situations usually degenerate. When I began to consider being a teacher... here you really can not react aggressively" (Workshop 2); “To express negative feelings I use the sandwich method: I say something positive, then try to identify and remedy the problem, and then end with something positive again, for example: I see you are an involved person, but... here would be the problem, I know that you will be more careful in the future" (Workshop 2). There are some examples for repressed feelings too: "if you say what your feelings are, the other will see that you are vulnerable" (Workshop 2); apathy, hostility expressed indirectly (Workshop 3).

About Asserting and defending your own rights the students describe a wide range of reactions, both from the sphere of passive, aggressive and assertive reactions: aggressive: "when you are frustrated you explode" or "with strangers... I destroy them to make sure they will not trouble me next time" (Workshop 1); passive (passive-aggressive): "If we find a colleague who understands and empathizes with us and we are delighted to engage in dialogue about the situation and then we take a position of resignation regarding the problem" (Workshop 3). "...from being upset, to anger, then to acceptance of the situation, resignation, after that another wave of anger..." (Workshop 3); "It could be all a misunderstanding, maybe he does have a problem (empathy towards the one who infringes on our rights1)" (Workshop 2); and assertive: "I would not give him the satisfaction. And I would try to be calm and to explain what he did wrong. When you raise your voice and you show indignation, you give satisfaction to the one who has infringed on your rights. If you maintain your firm position and dignity, that person will begin to back up"; "But if you treat things with gentleness, the other may understand that you are too good and that you are a sucker, it is advised that you show the person that you have certain principles and you deserve to be respected" (Workshop 1); "You may be aggressive at first, but then you negotiate until an agreement is reached" (Workshop 3). Face to face with authority, it is preferable not to demand rights in any way, but to preserve the appearance of obedience "if we have a conflict with a person in an authority position in the university... then as a student you shut up and do as told. There are situations in which we cannot manifest with first impulse, we must control ourselves one way or the other" (Workshop 1).

With regard to self-esteem and the desire for affirmation the strategies by which students independently assert their own personality, show self-confidence and self-promotion are as follows: ensuring a knowledge base allows you to affirm yourself-“To be sure of yourself, and to have a knowledge base that makes 
you feel confident" (Workshop 1); developing a moral system and principles that guide you to be authentic without being influenced by trends-"You are sure of yourself and of what you do and the opinions of others do not really affect you, but not out of wickedness, but simply you do not feel the need to care, and even if others have a negative opinion it does not affect you because you still believe in what you do and you mind your own business" or "You have the courage to be yourself in your art" (Workshop 1) or "He acts according to his own reasoning without letting himself be led by the flock spirit" (Workshop 3); it is associated with the power of expressing and maintaining your own perspective: "You have the power to express yourself, to do one thing, and then stay firm, bring arguments and stay strong, not giving up" (Workshop 2); and finally, self-esteem has as its source the assumption of responsibilities- "Assuming your responsibility and demonstrating to your loved ones that you have achieved your goals" (Workshop 1) or "I am responsible for my own decisions" (Workshop 2) or "I act in a personal way even if an older adult tries to offer me his solution" (Workshop 3).

\section{Findings}

Through this study we wanted to outline an image of the perception of the final years students who are preparing for the teaching career regarding to assertive competence in the successful development of their future profession. The three themes that have settled have allowed us access to a clearer picture of this aspect.

The first one, the meaning of assertive communication, reveals that in all of the three situations the participants demonstrate that they understand an important part of the concept. It observed that students are familiar with this concept and recognize a number of components of assertive communication. The most accessible are the elements of open and non-verbal supportive communication. Students then focus on expressing personal opinions and the ability to make a request, in order to succeed in argumentation and reasoning. Regarding the awareness of the need to express positive and negative feelings as a social practice, students refer only to the management of emotions in difficult situations. This kind of definition of assertive communication probably relates to their emotional and assertive needs in the context of professional development. The profession they are preparing for is one that asks for personal opinions, expression of individuality and to face the evaluation of teachers and the public. We note that no components are mentioned, such as saying "no" when the situation demands it, defending one's own rights without harming the other, or high self-esteem.

In close connection with this first theme there is also the second one-the role of assertive communication in the teacher-student relationship, which all participants appreciate and look for in their teachers. This theme is analyzed from the perspective of two directions: facilitators of assertive communication and inhibitory factors of assertive communication. It can be observed that students identify the important role teachers have in creating a democratic communica- 
tion environment in which the student has the right to express, make mistakes, experiment without fear of being criticized, ridiculed, and undermined. Among the skills that the teacher should have first is the supportive and facilitating attitude of group dynamics. Students express their need to interact with a group of peers who are united, cohesive, under the influence of a facilitator teacher. Students find examples of teachers who have trusted them to show their personality along with their cognitive skills. At the same time, it expresses the need, still unsatisfied, for teachers to act as competent authorities to guide them democratically, to facilitate their confidence and motivation in the learning process. In order for the teacher to be a good manager of the class, a "facilitating professor" of group dynamics, as the students call it, the empathic ability is also necessary. Students see empathy as working closely with assertiveness and assuring them of the understanding of the teacher, the feeling of being listened to and knowing that what they say is important. Empathy allows the teacher to convey the message that they are appreciated and their opinion counts, which would motivate them in their work.

The blockages in assertive communication are expressed in the behaviors of teachers and lead to under-motivating students, sub-realization, mistrust, stagnation or revolt: the ailment to listening to students, the attitude of superiority, the anchoring in traditional methods of working with students, the ease to forgive the colleagues who are attending courses less than others, extreme attitudes, passivity or aggression.

A third theme is represented by the ways in which assertive competence is expressed in its own behaviors, with three subtopics: the expression of positive and negative emotions, affirmation and defense of their own rights and self-esteem and the desire for affirmation. As for expressing emotions, we can observe some general notes.

The expression of positive feelings is, from the perspective of the participating students, specific to the value of close, intimate relationships. In positive relationships with others, the person expresses his politeness. They do not mention techniques for expressing positive feelings such as: smile and encouraging mimics, gratification, praise, verbal appreciation, compliment. It seems that students are aware of their need to get empathy and to experience positive relationships, but they do not know how to facilitate such an environment. There are also a number of differences in the reactions of participants in the three groups. Thus, the participants in the first workshop, students of the Faculty of Visual Arts, advocate expressing emotions anyway, whether positive or negative, and some of them question the expression of negative emotions in an assertive manner, even offering techniques that they use for staying away from aggression (awareness and self-control). Students from the Faculty of Musical Interpretation consider that expressing emotions, besides music, can make you vulnerable to others, and therefore tend to internalize them or to express them with caution. Moreover, they view this behavior as a virtue, considering that hiding the negative feelings make you stronger. 
Asserting their rights seems to be a great challenge. When their rights are violated, the participants in the first and third workshops describe a wide range of responses-passive, aggressive, assertive-but the workshop discussion managed to convince those who in the first phase tend to react aggressively that an assertive reaction is more productive, even if it is more difficult to put it into practice. The participants in the second workshop also recognize that they are rarely assertive, and the difficulties have different causes: self-protection, low self-esteem, passive or aggressive behavioral automatisms, or a lack of assertive behavior education.

For students involved in our research, self-esteem, comprised of a positive self-image, self-confidence and self-love, is anchored in the results that the school and social environment tends to validate and appreciate more, in assuming responsibilities and to the extent to which you manage to demonstrate the others that you are competent. Self-esteem is also made operational by courage, perseverance, firmness, personal style and being yourself. We note that although students take responsibility and shape their own style of artistic expression, their independence is one that oscillates between personal pleasure and the feedback of others. They need to develop skills to identify their own needs, to raise awareness of the personal resources and qualities they rely on, to capitalize on their potential and to develop it, and not try to demonstrate to others their value. Perhaps a study on extrinsic and intrinsic motivational factors and the motivational strategies used in their professional activity would complement the research already presented.

\section{Conclusion}

This paper emphasizes the importance of assertive communication in the development of the abilities of art students in the didactic career. Studies and research have proven the role of assertive strategies in personal development and selfrealization. It also emphasizes the influence of assertive didactic communication on the education of a democratic didactic style at future teacher students. The aim of the qualitative research was to collect and interpret empirical data to outline the perception of young people about their assertive behaviors and the role of assertive communication in the student-teacher relation. To accomplish this goal, we used the focus group qualitative research method. Invitations were sent to 40 students of the "George Enescu" University of Arts in Iasi, Romania. There were 28 students who responded to our invitation and thus three focus group workshops were organized. The group interview was conducted on the basis of a questions guide that aimed to investigate students' perceptions of assertiveness as a necessary competence for the teacher, the particularities of assertive communication in their relationship with teachers and assertive strategies that students apply in their social and school relationships. The students' answers were recorded audio and then transcribed. Every participant was expected to answer each question so that we could capture the full range of opinions. The analysis of 
the data was done by thematic decoupling as a form of content analysis.

We found that in terms of definition of assertive communication, one can see that students understand assertiveness as the clear and courageous communication of the verbal message, as well as the formulation of a request. There is no mention of the ability to refuse and establish boundaries, the constructive expression of negative emotions, or the assertion and defense of one's own rights. In teacher-student communication, students identify assertive behaviors that facilitate learning and active engagement: teacher's facilitator skills and empathy. It is also necessary to reduce the blockages and the frenzied factors of assertiveness: the attitude of superiority, autocratic teaching style, classical and non-activating teaching methods, passivity or aggressiveness. Regarding the assertive strategies used by students in relation to the teachers, there are three types of behavioral variants. The expression of positive and negative feelings is a difficulty, most of them being accustomed to not expressing these feelings, to internalize negative emotions in particular, and to express them only in a intimate relational context. We also encounter methods of expressing negative emotions, such as the "sandwich method" or "self-control that reduces aggression." The defense of their own rights in the teacher-student relationship does not manifest, the prevalent attitude being one of acceptance and "non-challenge". Negotiating or empathic self-asserting strategies are used in non-formal relationships, with aggressive reactions or withdrawal, resignation being predominant. Self-esteem and the desire for affirmation are expressed through perseverance in personal projects, responsibility and personal decision. We note that students are independent, able to take on responsibilities and decisions, but to move towards assertiveness requires developing intrinsic motivation strategies and harnessing their potential through group and community co-operation.

In conclusion, our research provides important insights into how assertiveness is promoted as a teaching strategy in university education with artistic profile and how assertive skills are developed in students who study to become teachers. The assertive communication courses that took place within the psycho-pedagogical training module broaden the students' sphere of knowledge, but the assertive skills of the students are in the process of being acquired and would expect a larger communication and training framework. The results of the study are consistent with international research proving the effectiveness of assertiveness training and its role in developing social skills. It would be opportune to expand this research by increasing the number of focus groups in other universities in the country to see if this style of teacher-student communication is specific to the geographical area or it is a model with wider social implications.

Therefore, the courses in the psycho-pedagogical training familiarize students with the notion of assertiveness, help them to understand new patterns of behavior, but it is also necessary to implement personal development modules that generate the transition from awareness to practice and transfer into the daily life of assertive communication strategies. In this way, in their role as teachers, they 
will be able to act as authorities exercising the power to motivate, activate the interest, stimulate the learning and forming of autonomous, creative young people with a high degree of self-satisfaction and quality of life, able to adapt and be active at a community level.

\section{Conflicts of Interest}

The authors declare no conflicts of interest regarding the publication of this paper.

\section{References}

Agada, J., Weaver, K. A., Kantamneni, P., \& Stalling, J. (1994). Defining Information Professionals: Assertiveness, Empathy and Anticipatory Socialization among Library, Business and Counseling Graduate Students. Library and Information Science Research Electronic Journal, 4, 1-5.

Alberti, R., \& Emons, M. (1970). Your Perfect Right: A Guide to Assertive Behavior. San Luis Obispo, CA: Impact Press.

Alberti, R., \& Emons, M. (2008). Your Perfect Right: A Guide to Assertive Behavior. San Luis Obispo, CA: Impact Press.

Ames, D. (2009). Pushing up to a Point: Assertiveness and Affectiveness in Leadership and Interpersonal Dynamics. Research in Organizational Behavior, 29, 111-133. https://doi.org/10.1016/j.riob.2009.06.010

Bakker, C. B., \& Bakker-Rabdau, M. K. (1973). No Trespassing; Explorations in Human Territoriality. San Francisco, CA: Chandler \& Sharp.

Bocoș, M. D. (2013). Instruirea Interactivă. Iași: Editura Polirom.

Bulai, A. (2000) Metode de cercetare calitativă. Focus-grupul în investigația socială, Ed. Paideia, Bucureşti.

Canter, L., \& Canter, M. (2001). Assertive Discipline. Los Angeles, CA: Canter \& Associates.

Chelcea, S. (2004). Focus grupurile. In S. Chelcea (Ed.), Metodologia cercetării sociologice. Metode cantitative şi calitative (ediția a II a, pp. 309-313). Bucureşti: Economică.

Cornelius, H., \& Faire, S. (1996). Ştiința rezolvării conflictelor. Bucureşti: Editura Ştiință şi Tehnică.

Evanghelidis, A. (2005). Evaluation of a Risk modeling Tool at the Business Case of eService Projects-Results from a Workshop in UK. In M. A. Wimmer, R. Traunmüller, Å. Grönlund, \& K. V. Andersen (Eds.), Electronic Government. EGOV 2005. Lecture Notes in Computer Science (Vol. 3591, pp. 105-112). Berlin, Heidelberg: Springer. https://doi.org/10.1007/11545156_10

Graham, R. S., \& Rees, S. (1991). Assertion Training: How to Be Who You Really Are. New York: Routledge.

Gultekin, A., Ozdemir, A. A., \& Budak, F. (2018). The Effect of Assertivness Education on Communication Skills Given to Nursing Students. International Journal of Caring Sciences, 11, 395-401.

Iluț, P. (1997). Interviul de grup şi focus-grup. In P. Iluț, Abordarea calitativă a socioumanului (pp. 92-98). Iași: Editura Polirom.

Jung, J. M. (2014). The Effect of an Assertiveness Training Program for Adolescents in Residential Care in South Corea. Asia Pacific Journal of Social Work and Development, 24, 285-299. https://doi.org/10.1080/02185385.2014.927329 
Krueger, R., \& Casey, M. A. (2005). Metoda Focus Grup. Iași: Editura Polirom.

Lazarus, A. A. (1971). Behavior Therapy and Beyond. New York: McGrow Hill.

Lazarus, A. A. (1973). On Assertive Behavior: A Brief Note. Behavior Therapy, 4, 697-699. https://doi.org/10.1016/S0005-7894(73)80161-3

Morgan, D. L. (1998). The Focus Group Guidebook. London, UK: Sage Publication Inc. https://doi.org/10.4135/9781483328164

Obey-Jordan, K. (2007). The Impact of Assertive Classroom Discipline on Social Skills. Education and Human Development (p. 416). Master's Theses, Brockport: State University of New York. https://digitalcommons.brockport.edu/ehd_theses/416/

Pânișoară, G., Sandu, C., Pânișoară, I. O., \& Duță, N. (2015). Comparative Study Regarding Communication Styles of the Students. Procedia-Social and Behavioral Sciences, 186, 202-208. https://doi.org/10.1016/j.sbspro.2015.04.066

Peneva, I., \& Mavrodiev, S. (2013). A Historical Approach to Assertiveness. Psychological Thought, 6, 3-26. https://doi.org/10.5964/psyct.v6i1.14

Phelps, S., \& Austin, N. K. (1987). The Assertive Woman: A New Look. Oakland, CA: Impact Publishers.

Rusu, M. (2017). Emoțiile-De la cunoaştere la autoreglare (Ed., p. 125). Ars Longa: Col. Academica, Iași.

Speed, B. C., Goldstein, B. L., \& Goldfried, M. R. (2018). Assertiveness Training: A Forgotten Evidence-Based Treatment. Clinical Psychology Science and Practice, 25, e12216. https://doi.org/10.1111/cpsp.12216

Whittake, P. J. (2010). Do Academic Competencies Relate to "Real Life" Public Health Practice? A Report from Two Exploratory Workshop. European Journal of Public Healt, 20, 8-9. https://doi.org/10.1093/eurpub/ckp157

Zappas, R. K. (2008). CSI for Engineers? Workshop Explores Prime-Time Appeal of Engineering Drama. Journal of the Minerals, Metals and Material Society, 60, 72.

https://doi.org/10.1007/s11837-008-0022-2 